\title{
Effectiveness of a holistic neuropsychological rehabilitation program using virtual reality
}

\section{Eficácia de um programa de reabilitação neuropsicológica holística usando realidade virtual}

\begin{abstract}
Acquired brain injury (ABI) is associated with severe functional consequences at several levels: personal, psychological, social, physical, economic, and systemic. The main objective of the present study is to show the potential of applying virtual reality (VR) in neuropsychological rehabilitation and the consequent psychological and cognitive improvement of the person with ABI. A total of 27 participants of both sexes with moderate or severe ABI participated in an investigation in a clinical trial-type design with pre-test and post-test. Participants in the experimental group $(n=8)$ underwent a remote holistic neuropsychological intervention program supported by a VR platform: the Virtual Centre for the Rehabilitation of Road Accident Victims (VICERAVI). The experimental group results were compared with a first control group $(n=10)$ that underwent a conventional holistic neuropsychological intervention face-to-face program; and with a second control group that did not have any neuropsychological intervention $(n=9)$. We conclude that the VR-based neuropsychological rehabilitation program (NRP) at a distance produces better cognitive results in general cognitive functioning, learning, memory, and executive functioning than the conventional face-to-face NRP. Still, at the psychosocial level, the conventional NRP obtained results similar to those of the VRbased NRP, which did not produce significant improvements. Thus, the study results suggest that the development of VR-based holistic NRPs may benefit the autonomy of people with ABI.
\end{abstract}

Keywords: acquired brain injury, neuropsychological rehabilitation, virtual reality

\section{RESUMO}

A lesão cerebral adquirida (ITB) está associada a graves consequências funcionais a vários níveis: pessoal, psicológico, social, físico, económico e sistémico. O objectivo principal do presente estudo é mostrar o potencial da aplicação da realidade virtual (RV) na reabilitação neuropsicológica e a consequente melhora psicológica e cognitiva da pessoa com ITB. Um total de 27 participantes de ambos os sexos com ITB moderado ou grave participaram de uma investigação com um desenho do tipo ensaio clínico com pré-teste e pós-teste. Os participantes do grupo experimental $(n=8)$ foram submetidos a um programa de intervenção neuropsicológica holística remota apoiado por uma plataforma de RV: o Centro Virtual de Reabilitação de Vítimas de Acidentes de Trânsito (VICERAVI). Os resultados do grupo experimental foram comparados com um primeiro grupo de controle $(n=10)$ que foi submetido a um programa de intervenção neuropsicológica holística convencional face a face. Um segundo grupo de controle não teve qualquer intervenção neuropsicológica $(n=9)$. Concluímos que o programa de reabilitação neuropsicológica baseado em RV (NRP) à distância produz melhores resultados cognitivos no funcionamento cognitivo geral, aprendizagem, memória e funcionamento executivo do que o NRP convencional face a face. Ainda assim, o NRP convencional obteve resultados semelhantes aos do NRP baseado em VR, que não produziu melhorias significativas no nível psicossocial. Assim, os resultados do estudo sugerem que o desenvolvimento de NRPs holísticos baseados em RV pode beneficiar a autonomia das pessoas com ITB.

Palavras-chave: lesão cerebral adquirida, reabilitação neuropsicológica, realidade virtual

Submission: 19/03/2021 | Accepted: 09/06/2021

Liliana Mendes. Research Center in Sports Sciences, Health Sciences and Human Development (CIDESD), at the University of Trás-os-Montes and Alto Douro, Vila Real, Portugal.e-mail: lilianavm@utad.pt

Luís Paulo Reis. Laboratory of Artificial Intelligence and Computer Science (LIACC) at the University of Porto, Porto, Portugal. Fernando Barbosa. Laboratory of Neuropsychophysiology, at the Faculty of Psychology and Educational Sciences of the University of Porto, Porto, Portugal. 
Virtual reality (VR) is an emerging technology whose benefits in research, treatment, and rehabilitation have been evidenced in recent decades (Schultheis \& Rizzo, 2001). VR can be implemented in an immersive or non-immersive way. Immersive VR gives the user the sensation of inclusion or presence because they feel inside the virtual environment, where they can interact with the various elements that make up the scenario through specific devices, such as viewing helmets, gloves, and headphones. In non-immersive VR, the user does not have the sense of inclusion, as it only allows the viewing and handling of 3D images through a computer (Rose et al., 1999).

Currently, there are open-source non-immersive environments (e.g., OpenSimulator) online where users are represented by avatars (virtual characters customizable by the user that allow them to move around the virtual environment and interact with objects or other characters in that environment). Besides being often used to teach competencies (e.g., skills, knowledge), these platforms allow for simulations applicable to clinical and social areas (Jarmon et al., 2008; Riva, 2009). By enabling avatars to establish verbal and non-verbal communication (gestures, facial expressions) with other users, these scenarios become particularly interesting for the rehabilitation of social interaction skills. Thus, VR has been gathering favorable evidence for its use as an auxiliary method in various areas of health, including the following: (i) psychotherapy (Botella et al., 2004; Glantz et al., 2003); (ii) behavioral therapy (Riva et al, 2002), particularly in the treatment of post-traumatic stress disorder and the reduction of associated symptoms, such as anxiety and depression (Kenny et al, 2008; Kenny et al., 2009; Rizzo et al., 2006; Wiederhold \& Wiederhold, 2008), in the treatment of specific phobias (Côté \& Bouchard, 2008), and in eating disorders (Riva et al., 2002; Riva et al., 2004); (iii)in autistic spectrum disorder (Pioggia et al, 2008); (iv) in the reproduction and training of routine activities in parkinsonism (Albani et al., 2002); (v) in the simulation of auditory and visual hallucinations in schizophrenic patients (Yellowlees \& Cook, 2006); (vi) in the reduction of distractibility symptoms for people with attention deficit hyperactivity disorder (Adams et al., 2009; Rizzo et al, 2000); (vii) in the assessment of driving ability after acquired brain injury (ABI) (Lengenfelder et al., 2002; Léon-Carrion et al., 2005; Pietrapiana et al., 2005), among others.

VR has been used both for neuropsychological assessment purposes (Rizzo et al., 2004; Schultheis et al., 2002) and neuropsychological rehabilitation. Although VR is still at a very early stage, it has shown good results in rehabilitating several cognitive domains, namely, visuospatial abilities, attention, memory, and executive functioning. A study carried out by Rizzo et al. (2004) showed that VR is a relevant aid in cognitive training. Egan et al. (2005) note that specific online training for people with traumatic brain injury (TBI) produces significant improvements in concentration, memory, and motivation and enables the learning of strategies and social skills with an important psychological impact, preventing isolation. Moreover, Cicerone et al. (2011) consider that using computers is recommended in post-acute rehabilitation after TBI to improve attention. Thus, people with cognitive and/or functional changes and neurological and learning disorders resulting from ABI may benefit from VR applications (Cicerone et al., 2011; Egan et al., 2005; Rizzo et al., 2000; Rizzo et al., 2004).

Currently, sufficient evidence has been gathered on the effectiveness of the holistic model of neuropsychological rehabilitation, which consists of creating and fostering a therapeutic environment capable of guiding the individual and the family, and their adaptation to the new state is systematically monitored (Ben-Yishay, \& Diller, 2011). The same 
model is recommended in a post-acute phase after TBI (Cicerone et al., 2011). However, it remains to be seen whether the same model can be reproduced in a VR platform maintaining its effectiveness and qualities. Due to its intrinsic characteristics, VR is probably the best option when the replica of a certain reality in a controlled and safe context for skill-training purposes is needed (Gamito et al., 2010). Studies on VR use in the neuropsychological rehabilitation of people with ABI have shown promising results, but further study of its potential benefits is urgent. Moreover, studies specifically on holistic neuropsychological rehabilitation using virtual environments are non-existent. Given its positive impact on the rehabilitation of people with ABI (Cicerone et al., 2008; Coetzer, 2008; Wilson, 2002) and the fact that VR enables real-life simulation in situations of good ecological validity, we sought to assess the effectiveness of combining holistic neuropsychological rehabilitation with the technological possibilities of VR platforms.

In this sense, the main objective of this study was to demonstrate the possibility and effectiveness of using virtual environments in the holistic neuropsychological rehabilitation of ABI. Three steps were followed to achieve the main objective:

1. to develop a holistic neuropsychological rehabilitation program (NRP) supported by a VR platform (OpenSimulator);

2. to study the applicability of ecological virtual environments to the main components of holistic rehabilitation, namely, psychosocial rehabilitation activities and training of the most common cognitive domains (such as attention, memory, and executive functioning) in individuals clinically diagnosed with a moderate-to-severe brain injury after TBI;

3. to compare the effectiveness of the program developed with that of a face-to-face holistic rehabilitation program, using multiple outcome measures of cognitive functioning, emotional stability, and psychosocial functioning (quality of life).

We expected that the VR-based NRP developed would produce results equivalent to those of the conventional program regarding cognitive and psychosocial functioning. On the other hand, we anticipated that the face-to-face intervention would be more successful concerning the affective dimensions (i.e., reduction of depressive and anxious symptoms). Thus, we established three operational hypotheses:

- Hypothesis 1 - participants in the VR-based NRP show marked improvement in measures of cognitive, affective, and psychosocial functioning compared to people with ABI who do not participate in any intervention.

- Hypothesis 2 - the VR-based NRP produces results equivalent to those of the conventional program (face-to-face) in the various cognitive domains and psychosocial functioning.

- Hypothesis 3 - the conventional program produces better results than the VR-based NRP in the affective domain.

\section{METHODS}

Participants

All participants had been diagnosed with moderate or severe ABI. Three groups of participants were investigated, two groups randomly and one by convenience, in a clinical trial-type design with pre-test and post-test:

1. the experimental group (EG, $n=8$ ) carried out a holistic neuropsychological intervention program supported by a VR platform (VICERAVI).

2. control group I (CGI, $n=10$ ) carried out a conventional holistic neuropsycholo- 
gical intervention program in a face-to-face setting.

3. control group II (CGII, $n=9$ ) was not subjected to intervention, having only performed the pre and post-test (i.e., the neuropsychological assessment).

The EG and CGII participants were recruited from the individuals admitted to a center for medicine and rehabilitation in Portugal to comply with a physical medicine and rehabilitation program (comprising swimming, physiotherapy, speech therapy, and occupational therapy). The following inclusion criteria were applied to recruit participants for these groups: (1) moderate-to-severe ABI; (2) ages 17 years or older; (3) motivation to integrate an intensive rehabilitation program; (4) ability and availability to participate in group activities; and (5) not having previously participated in NRPs. The exclusion criteria were: (1) diagnosed psychopathological disorder or psychotic symptomatology; (2) interpersonal relationship problems, irritability or impulsivity that would prevent interaction with others; (3) illicit substance use/ abuse in the six months before the start of the program; and (4) intellectual deficit or general functional disability that would prevent understanding or performing the tasks of the rehabilitation program. The inclusion and exclusion criteria for the CGI were identical to those of the EG and CGII. However, the CGI participants were recruited in a Portuguese vocational rehabilitation center and investigated later than the other groups.

The sociodemographic and clinical data of the sample with greater relevance to the study are presented in Table 1 . The groups were paired by age, sex, vertical education, time since the injury, and injury severity. Homogeneity between the three groups was statistically confirmed for the sociodemographic variables of interest (age, sex, vertical education) and for the time since the brain injury and its severity.

Table 1

Sociodemographic characteristics of each of the sample groups.

\begin{tabular}{cccccccccccc}
\hline & \multirow{2}{*}{$n$} & \multicolumn{2}{c}{ Age (years) } & \multicolumn{2}{c}{ Sex } & \multicolumn{2}{c}{ Education (years) } & \multicolumn{2}{c}{ TSI (months) } & \multicolumn{2}{c}{ Severity } \\
\cline { 2 - 12 } & & $M$ & $S D$ & Male & Fem. & $M$ & $S D$ & $M$ & $S D$ & severe & mod. \\
\hline EG & 8 & 37.0 & 12.17 & 8 & 0 & 10.37 & 3.35 & 5.09 & 4.73 & 6 & 2 \\
CGI & 10 & 37.2 & 10.13 & 8 & 2 & 9.00 & 3.66 & 53.00 & 44.37 & 9 & 1 \\
CGII & 9 & 39.4 & 16.19 & 6 & 3 & 9.63 & 3.90 & 1.66 & 0.90 & 7 & 2 \\
TOTAL & 27 & 37.8 & 12.83 & 22 & 5 & 9.66 & 3.63 & 19.92 & 16,67 & 22 & 5 \\
\hline
\end{tabular}

Nota: EG = Experimental Group; CGI = Control Group I; CGII = Control Group II; TSI = time since injury.

\section{Instruments}

The anamnesis data were collected through a questionnaire about sociodemographic information, including the following independent variables or variables to control: age, marital status, education, profession and/or employment situation, current health status, information about the type of accident and consequences, and Glasgow Coma Scale score. We used the instruments described below pre and post-test to collect data on the dependent variables.

\section{Evaluation of Quality of Life}

Quality of life was assessed using a Portuguese version of the Quality of Life after Brain Injury (QOLIBRI) questionnaire (Guerreiro et al., 2012). The QOLIBRI questionnaire (Truelle et al., 2010; Von Steinbüchel et al., 2010) allows estimating the quality-of-life profile of people with ABI in six domains. It consists of 43 items organized 
into two parts. The first part is divided into four factors to assess life satisfaction: general (6 items), cognition (7 items), self (7 items), daily life and autonomy (7 items), and social relationships (6 items). The second part is divided into two factors - the emotional and the physical, consisting of five items each, to assess the degree of discomfort that people feel regarding possible emotional and physical changes. Each item is answered on a five-point Likert-type scale ( $1=$ not at all; $5=$ very much).

\section{Emotional stability assessment}

A Portuguese version of the Hospital Anxiety and Depression Scale (HADS; Zigmond \& Snaith, 1983, Portuguese version by Pais-Ribeiro et al., 2007) was applied to assess emotional stability. The HADS comprises 14 items divided into two factors: anxiety (7 items) and depression (7 items). Each of the items is answered on a four-point Likert-type scale ( $0=$ low; $3=$ high). The final scores of each subscale can range between 0 and 21, resulting from the sum of the points from each factor. Anxiety and depression can be classified as absent (0-8), mild (8-10), moderate (11-15), and severe (16-21). Although it is possible to calculate the total HADS score, scoring the anxiety and depression factors separately provides us with specific and, therefore, more relevant information on each of these domains of affectivity. In addition to these scales, we used the neuropsychological assessment protocol briefly described below to assess the mental functions under study.

Screening of neurocognitive functioning

We used a Portuguese version of the Montreal Cognitive Assessment (MoCA; Nasreddine et al., 2005; Portuguese version by Freitas et al., 2010) for general screening of neurocognitive functioning. The MoCA is a brief instrument that allows screening of eight cognitive domains: executive function, visuospatial ability, memory, attention, concentration, working memory, language, and orientation. The administration time is approximately 10 minutes, and the final score may range between 0 and 30 points, with values between 26 and 30 indicating normal cognitive functioning and below 26 indicating the presence of a deficit. According to Freitas et al. (2010), this instrument is more sensitive than similar instruments in situations of mild cognitive impairment and in a population with a higher level of education.

Mnestic functioning

We applied the Spatial Location (SL) and the Letter and Number Sequence (LNS) subtests of the Wechsler Memory Scale or Wechsler Memory Scale III (WMS-III; Wechsler, 1998) to assess working memory. The SL subtest uses visual stimuli, and the examinee is asked to point to a 3D board (numbered from 1 to 10) following two instructions: in the direct order, the examiner points sequentially to items (numbers) on the board, and the examinee has to repeat the same sequence of touches; in the reverse order, the examinee has to touch the items on the board following the examiner's reverse order of touches. The difficulty level increases from level 1 (two items) to level 8 (nine items). The LNS subtest uses auditory stimuli, where the examiner orally presents different sequences of letters and numbers alternately. Level 1 begins with a sequence of two items, and at the higher level (7), eight items are presented. Applying these subtests allows assessing working memory changes and controlling for potential sensory perception deficits.

We applied the Hopkins Verbal Learning Test (HVLT; Brandt \& Benedict, 2001) to assess verbal learning and memory. The task consists of reading a list of 12 words to the participant, who is then asked to repeat as many of those words as possible. This task should be repeated three times (reading and recall). After a 20-25-minute break, the participant is asked again to recall as many words as 
possible. Then, a list of 24 words is read, and the participant is asked to mark those from the initial list (only 12 words). The results are obtained by calculating Total Recall (total sum of correct answers on trials 1, 2, and 3), Learning on the third trial (number of correctly marked words), Delayed Recall (number of correct answers on trial 4), and Semantic Categories (immediate recognition discriminability [IRD], which corresponds to the total number of true positives and total number of false positives).

\section{Attentional functioning}

For this purpose, we used Forms A and B of the Trail Making Test (TMT), which assesses attention, processing speed, mental flexibility, and spatial organization and is sensitive to the presence of brain damage. Form A requires the participant to draw lines to interconnect numbers from 1 to 25 that are randomly distributed. Form $B$ requires the person to connect numbers (1 to 13) and letters (A to $\mathrm{L}$ ) following a sequence (e.g., 1-A-2-B-3-C-4-D...). Time is clocked for both forms, and the score represents the amount of time spent to complete each part of the task. A performance time of up to 29 seconds for Form A and 75 seconds for Form B is considered "normal." Higher scores indicate greater cognitive impairment, and clinically significant cut-off points are 78 seconds in Form A and 273 seconds in Form B (Gaudino et al., 1995).

We also applied the $\mathrm{d} 2$ Attention Test (Brickenkamp, 2002) to assess selective attention and sustained attention. This instrument consists of 14 lines with 47 characters each, corresponding to letters $\mathrm{d}$ or $\mathrm{p}$. During this test, the person is instructed to look for all the letters $d$ with certain characteristics and mark them in a maximum time of 20 seconds per line. The application time can be up to 10 minutes. The results are measured according to the following indicators: Total Hits (number of characters correctly marked on the
14 lines); Total Effectiveness (total characters processed minus total errors); Concentration Index (total hits minus total type 2 errors, that is, marking irrelevant characters); and Percentage of Errors (percentage of errors made throughout the test).

\section{Evaluation of Executive Functioning}

For this purpose, we used the Wisconsin Card Sorting Test (WCST; Berg, 1948, Spanish version by Heaton et al., 2001), one of the commonly used instruments to assess executive functioning. The WCST involves the development of abstract concepts, planning, sequencing, and mental flexibility, or the maintenance of cognitive context. The test consists of presenting a set of cards containing geometric figures in different numbers, colors, and shapes to the examinee, who must choose how to pair them with model cards according to one of these categories (color, number, or shape). With positive feedback, they should continue with the chosen category, but if the pairing decision is wrong, the examinee can choose an alternative category until they get it right. Each category is complete after ten consecutive correct answers, and a new category must then be proposed (e.g., switching from color to shape). The task ends after the participant has completed six complete categories (color-shape-number-color-shapenumber) or finished the 128 cards that make up the test. In terms of results, we considered the following measures of executive functioning: number of trials; total number of errors; number of perseverative responses; number of perseverative errors; number of non-perseverative errors; number of completed categories; and failures to maintain attitude.

In addition to the WCST, the Stroop Test (Golden, 1978; Golden \& Freshwater, 2002, Portuguese adaptation by Fernandes, 2013) was administered, which allows assessing cognitive flexibility and concentration based on the presentation of three sheets with 100 items each, presented in five columns of 20 
items each. The first sheet has the words blue, green, and red randomly distributed and printed in black color, and the examiner asks the person to quickly read the words in vertical order. The second sheet consists of randomly distributed Xs printed in blue, green, and red, and the task is to name the colors in which the Xs are printed vertically. The third sheet evaluates the Stroop effect since it is composed of words that name colors that are incongruent with the colors in which they are printed, and the examinee is instructed to read vertically the color of the word printed and not the word itself. The naming time for the items per sheet is 45 seconds. The test result is based on the calculation of the interference index, measured by the result of the difference between the Word-Color (WC) and the estimated WCs (Word*Color/Word+Color).

\section{Language Assessment}

A Portuguese version of the Token Test (De Renzi \& Vignolo, 1962; Portuguese version by Jesus \& Aguiar, 2014) was used to assess language alterations, specifically the comprehension of simple and complex orders associated with aphasic disorders. This test consists of 20 geometric pieces of different shapes (squares and circles), sizes (small and large), and colors (yellow, blue, green, and white) that are arranged on the table in a defined order. The version used in this study is divided into six parts (A-F) and consists of 39 instructions where the examinee is asked to manipulate certain pieces according to the instructions. The total score consists of the sum of correct answers up to a maximum of 163 points.

Virtual Centre for the Rehabilitation of Road Accident Victims (VICERAVI)

The VICERAVI (see Figure 1) is a virtual environment and user simulation platform in a non-immersive system that simulates a virtual rehabilitation center. It was developed in OpenSimulator (version $0.7 .3,2012$ ) by a multidisciplinary team from the Faculty of
Engineering of the University of Porto and specifically designed to host a holistic NRP, with group and individual activities, for people with ABI. It is connected to the Neuropsychological Enrichment Program of the University of Minho (NEP-UM), where serious games were programmed for specific training of attention, memory, language, and executive functioning.

The OpenSimulator is an open-source 3D applications server that allows the creation of virtual environments that can be accessed online and for free (similar to Second Life), where users are represented by avatars. It is configured as a meeting space for activities and tasks, individually or in a group, important in neuropsychological rehabilitation. Precisely for these reasons, this was the environment selected to develop and host VICERAVI.

Users access the platform whenever they want, using a username and password. In this space, they can create and physically change an avatar to represent them, navigate the VICERAVI, and interact with other participants. The VICERAVI's space has a reception area with a desk and sofas, where there is a receptionist (programmable as a virtual agent that may interact with users). To the right of the reception desk is a room with nine computers that allow participants to access the NEP-UM platform and perform cognitive rehabilitation training. The room to the left is intended for group activities, consisting of a table with chairs and nine white couches, except for two red ones, which are intended for group intervention facilitators or for participants in certain techniques that are implemented in psychosocial rehabilitation sessions (such as the "hot seat").

The development of this platform went through several phases. In Phase 1, we conducted a literature review to survey development methods. Then, in Phase 2, which corresponds to the Conceptual Design, we met with the technical team to define the serious 
games to be developed for each cognitive domain, their difficulty levels, and the conditions for developing the virtual environment according to the requirements of the holistic NRP sessions.
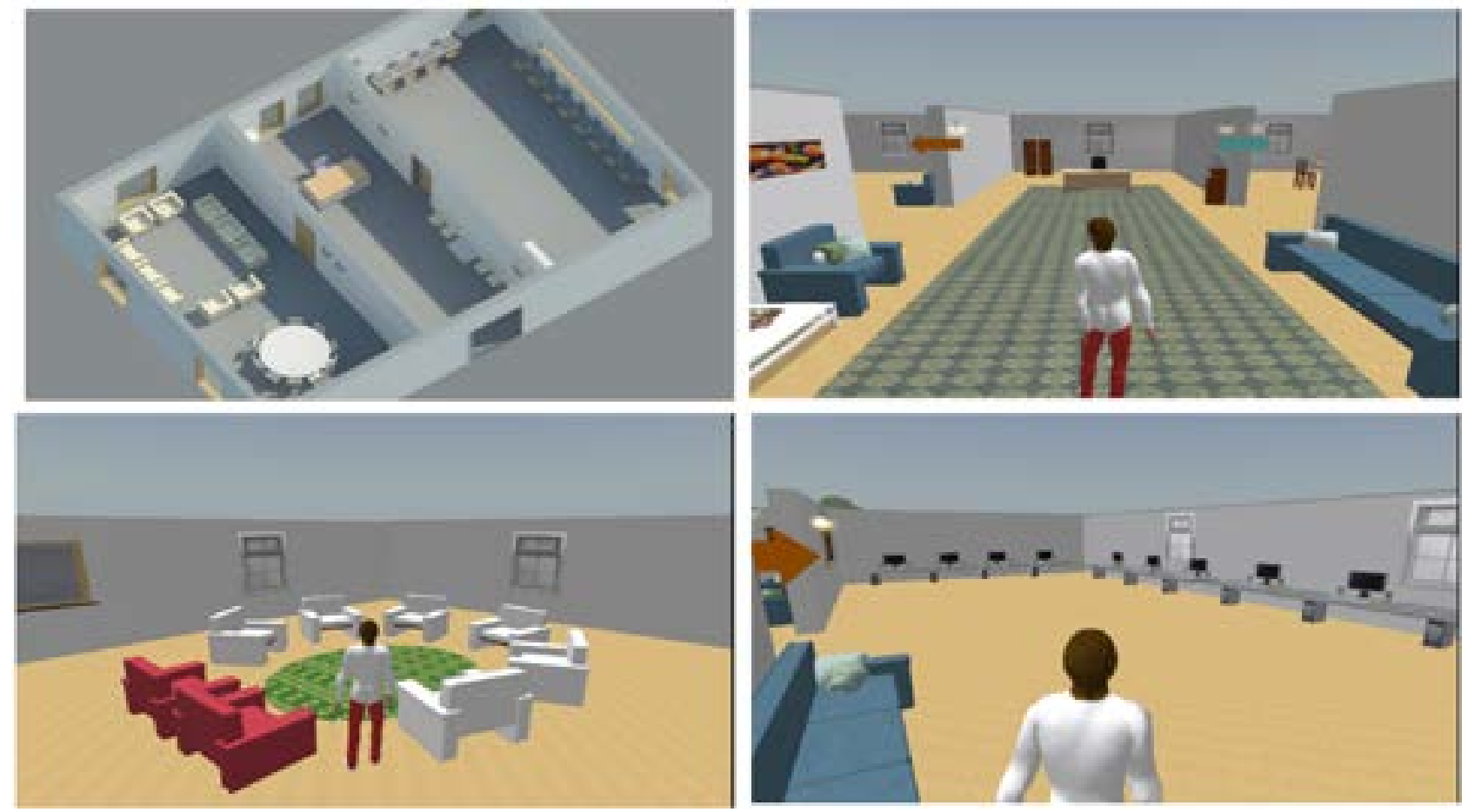

Figure 1. Virtual Centre for the Rehabilitation of Road Accident Victims - VICERAVI (developed in OpenSimulator).

In Phase 3, we met with the IT technicians and a psychologists' team from the rehabilitation centers to identify and minimize possible difficulties at the technical level and in the interaction with the VR platform that could be caused by participants' constraints. In subsequent phases, we developed the VICERAVI (Phase 4) and the games that integrated the NEP-UM (Phase 5). Finally, in Phase 6, we proceeded to the implementation of the holistic rehabilitation program.

Neuropsychological Enrichment Program University of Minho (NEP-UM)

The NEP-UM is a cognitive training platform accessible online, developed by the Computer Graphics Centre and the School of Psychology of the University of Minho, Portugal, aimed at professionals and individuals involved in the process of cognitive rehabilitation in the context of various neuropathologies and psychopathologies. Thus, it was integrated into the VICERAVI. The platform allows the clinician to prescribe specific sessions and exercises for each participant, monitor performance throughout the tasks, and detailed progress reports. This platform has the advantage of allowing the performance of several tasks with different stimuli, considering the real difficulties of the user. In addition to performing the tasks, the user is also allowed to consult the instructions for the session and repeat it, if necessary and the clinician allows it, as well as obtain real-time feedback and reports on their performance in the session.

For this study, cognitive training tasks were designed and developed in the domains of attention, memory, language, and executive functioning (see Table 2), with five levels of difficulty: level 1 (low); level 2 (medium-low); level 3 (intermediate); level 4 (medium-high); and level 5 (high). 
Table 2

Structure and characterization of cognitive domains and subdomains for which rehabilitation tasks were developed.

\begin{tabular}{|c|c|c|c|c|}
\hline Domain & $\begin{array}{l}\text { Attention and } \\
\text { Perception }\end{array}$ & Memory & Language & $\begin{array}{l}\text { Executive } \\
\text { Functioning }\end{array}$ \\
\hline \multirow[t]{4}{*}{ Subdomains } & $\begin{array}{l}\text { Selective Auditory } \\
\text { Attention }\end{array}$ & Working memory & Lexicon & $\begin{array}{l}\text { Planning and } \\
\text { problem-solving }\end{array}$ \\
\hline & $\begin{array}{l}\text { Selective visual } \\
\text { attention }\end{array}$ & Short-term memory & Syntax & Abstract reasoning \\
\hline & & & Semantics & Prospective memory \\
\hline & & & Understanding & \\
\hline
\end{tabular}

The development of the tasks was inspired by other cognitive rehabilitation programs available in the market that are used in conventional NRP (namely Rehacom), carried out by one of the control groups (CGI) and with which we intended to compare the holistic program supported in VICERAVI. We always tried to make sure that the tasks were ecological (that is, that they involved everyday stimuli) and could be done remotely (online), at any time and place, with as much autonomy as possible. It should be noted that the difficulty in handling and using NEP-UM is quite low.

\section{Procedures}

After approval by the Ethics Committee of the rehabilitation centers and once the feasibility of the program for the selected individuals was confirmed by the clinical directors, all participants and their families were contacted and voluntarily joined the study through informed consent. In compliance with ethical principles, anonymity was safeguarded, and participants were informed that the results of the neuropsychological assessments resulting from the pre-test, post-test, and follow-up could be used for clinical purposes, as well as for the present or other research works. We also clarified that they would be free to drop out of the study, including the rehabilitation program, at any time, without any consequences.

According to the established protocol (pre and post-test evaluation), psychologists from the rehabilitation teams of each center collaborated in the individual neuropsychological evaluation in random order. The neuropsychological evaluation was divided into two sessions, with a maximum duration of two hours. After collecting data from the pre-test phase, the participants were randomly assigned to the EG, included in the holistic online NRP administered through VICERAVI, and CGII, which did not undergo any neuropsychological intervention during the study period. Participants of the CGII were explained that they would have the opportunity to benefit from an NRP once the study ended and that, if they wished to join a rehabilitation program at any other institution during the study, they should inform the researcher and be excluded from the present study.

The holistic program to which the EG was exposed lasted for 16 weeks, involving cognitive, affective, and psychosocial rehabilitation components, administered online in a VR environment. Cognitive training sessions were held three times a week, and affective and social skills sessions were held twice a week. Each session lasted between 40 and 60 minutes. In total, the participants in the EG carried out a program of 80 sessions (49 cognitive training and 31 affective and psychosocial intervention) of individualized design and adjusted based on each participant's progress, maximizing the users' 
autonomy and efficiency.

The cognitive training component of the program focused on attention, memory, language, and executive functioning to remedy cognitive deficits or compensate for their consequences through exercises of difficulty adjusted to each participant's abilities according to the neuropsychological evaluation results.

The main objective of the affective and psychosocial training component was to promote social skills and self-help relationships through group sessions, involving techniques to promote self-esteem, problem- -solving, and psychoeducational techniques aimed at promoting the understanding of anxiety, stress, and fear mechanisms.

Besides an initial face-to-face session and another at the end of the program, involving all the participants and the researcher in charge, the whole training, including cognitive, affective, and psychosocial components (see Figure 2), was administered via the VR platform VICERAVI. For the technical and logistical conditions to be equivalent for all participants, the sessions took place in the computers of the rehabilitation center where the samples were recruited.

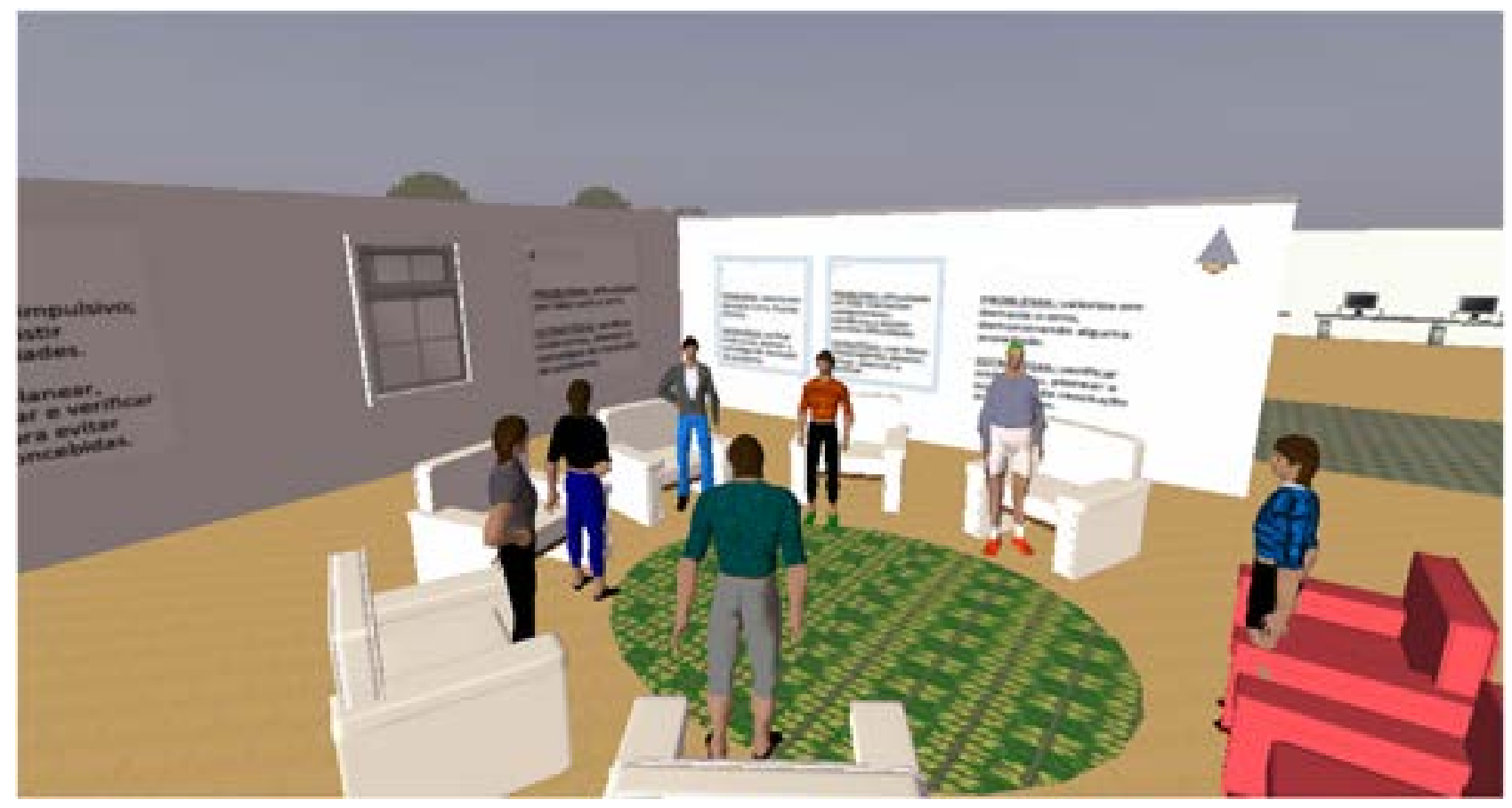

Figure 2. Example of a "hot seat" psychosocial rehabilitation session, in which participants and therapist are represented by an avatar.

For the development of the psychosocial rehabilitation sessions (as in conventional NRP), posters (see Figure 3) were displayed on the walls of the VICERAVI room, and participants could consult them at any time. These contain information about problems and resolution strategies identified by each participant or words that characterize the relationship, moral character, temperament, and main steps to perform the tasks, which are important to guide the group.
At the end of the intervention phase, the post-test neuropsychological assessment was performed. In this evaluation, the same instruments and the same procedures as in the pre-test were applied, but an additional tailor-made questionnaire was administered in the end to assess satisfaction with the NRP.

As for CGI, which underwent the conventional holistic program, similar to the other groups, a pre-test neuropsychological assessment was performed using the same instru- 

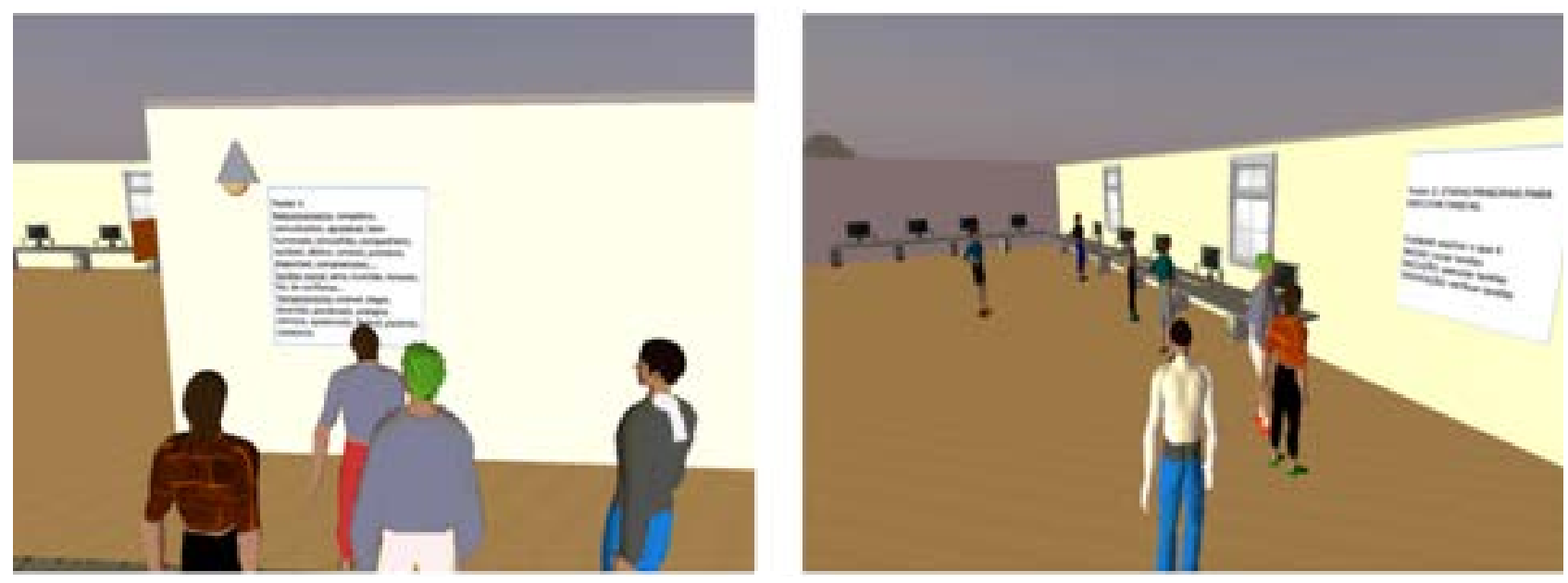

Figure 3. Poster consultation by participants during one of the psychosocial rehabilitation sessions.

ments and procedures. These participants were already a group that would start a conventional holistic NRP in another rehabilitation center (convenience sample).

The program implemented to this control group adopted the same theoretical rationale and holistic perspective of the rehabilitation program administered through VICERAVI, as advocated by Ben-Yishay (2000, cited in Guerreiro et al., 2009). Also, in this case, the main objective is to carry out an individualized rehabilitation program that provides the best level of biopsychosocial functioning to the person. The fulfillment of this goal also involves a cognitive rehabilitation component, containing similar tasks for training attention, memory, language, and executive functioning to remedy or compensate for cognitive deficits, and an intervention component in the affective and psychosocial domain. The latter involves group activities like those implemented with the EG, aimed at promoting psychosocial adjustment through the development of adaptive and coping skills within interpersonal relationships and the generalization of skills developed in the therapeutic context to the different contexts of daily life (Wilson et al., 2000). Therefore, this program is based on the same rationale as the one offered to the EG, shares the same purpose, and materializes it in the same type of cognitive training activities, supporting it with tasks that may be somehow related to daily life activities, to promote ecological validity and, thus, facilitate generalization to daily life situations and greater autonomy of the person. It also contains activities that aim to facilitate interpersonal relationship skills and promote emotional adjustment to the new life and functioning condition. However, the face-to-face program incorporates components that were not offered at VICERAVI, namely individual psychological support. In addition, the program administered to this control group was longer (22 weeks) and more intensive ( 22 hours of intervention per week).

In addition to the components described above, the NRP for the control group also included training in information and communication technologies, a project for professional reintegration focused on developing employability skills, or the preparation of participants for integration in other services that promote an active life (e.g., training courses or occupational activities). It was also accompanied by a group intervention with families, and, depending on the specific needs of each participant, physiotherapy/hydrotherapy, occupational therapy, and speech therapy could be offered. These services were also available to participants in the other study groups.

At the end of the program, the neurop- 
sychological re-evaluation was performed using the same instruments and following the same procedures that were adopted with the other groups.

Data treatment and analysis

Data were initially recorded in Excel and later transferred to the Statistical Package for the Social Sciences, version 17.0 (2008, SPSS, Chicago, Illinois, USA) for treatment and analysis. In addition to descriptive statistics (measures of central tendency and dispersion), we performed a mixed repeated-measures ANOVA for each dependent variable, entering the Group (EG, CGI, or CGII) as an inter-subject factor and the Moment of neuropsychological assessment (pre-test, post-test) as an intra-subject factor, to test the hypotheses that guided this study (with $p=.05$ ). Prior to the analyses of variance, the Shapiro-Wilk test was applied to verify the normality of the samples, the Levene test to examine homogeneity, and the Mauchly test to verify the assumption of sphericity.

Hypothesis 1. To test this hypothesis, we used a mixed repeated-measures ANOVA, in which the Group (EG, CGII) was used as an inter-subject factor, while the Moment (pre-test, post-test) was used as an intra-subject factor. With respect to the cognitive dimensions, the repeated measures evaluated were, independently, the scores for general cognitive functioning (MoCA), learning and memory, focused attention, language, processing speed, and executive functioning. In the affective dimension, depression subscale (HADS) and anxiety subscale (HADS) scores were entered as dependent variables, and, finally, in the case of psychosocial functioning, the QOLIBRI score was entered as a dependent variable. Post-hoc analyses (Holm-Sidak) were always performed, not to decompose the results for hypothesis testing but also to verify the statistical pairing of the groups in the pre-test evaluation. All p-values were corrected for multiple comparisons by the False Discovery Rate (FDR; Benja- mini \& Hochberg, 1995) method.

Hypothesis 2. The effectiveness of VR-based NRP on cognitive functioning was also assessed using a mixed repeated-measures ANOVA, in which Group (EG, CGI) was entered as an inter-subject factor, while Moment (pre-test, post-test) was entered as an intra-subject factor. The repeated measures evaluated were general cognitive functioning, learning, and memory, focused attention, language, processing speed, and executive functioning in the cognitive dimension and the psychosocial dimension the QOLIBRI. The mean values and standard deviations of the results for both groups are presented in Table 3.

Hypothesis 3. To test this hypothesis, we also used a mixed repeated-measures ANOVA, in which the Group (CGI, EG) was used as an inter-subject factor, while the Moment (pre-test, post-test) was used as an intra-subject factor. In the affective dimension, depression subscale (HADS) and anxiety subscale (HADS) scores were entered as dependent variables and, finally. Post-hoc analyses (Holm-Sidak) were always performed, not to decompose the results for hypothesis testing but also to verify the statistical pairing of the groups in the pre-test evaluation. All p-values were corrected for multiple comparisons by the FDR (Benjamini \& Hochberg, 1995) method.

\section{RESULTS}

\section{Descriptive Statistics}

We first present the descriptive statistics (see Table 3) for the three groups in the pre and post-test, in terms of means (M) and standard deviations (SD) for the measures of general cognitive functioning, learning, and memory, concentrated attention, language, processing speed, and executive functioning. Descriptive statistics are also presented for measures of the affective dimension, namely depression and anxiety, and the psychosocial dimension, specifically quality of life. 
Table 3

Means $(M)$ and standard deviations (SD) for the three Groups regarding measures of general cognitive functioning (MoCA), learning and memory (LM), focused attention (FA), language (Lan), processing speed (PS), and executive functioning (EF), the affective dimension HADS Depression and Anxiety, and the psychosocial dimension QOLIBRI.

\begin{tabular}{lcccccccccccccc} 
& \multicolumn{4}{c}{} & \multicolumn{4}{c}{ EG $(n=8)$} & \multicolumn{4}{c}{ CGI $(n=10)$} & \multicolumn{4}{c}{ CGII $(n=9)$} \\
\cline { 2 - 15 } & \multicolumn{2}{c}{ Pre-Test } & \multicolumn{2}{c}{ Post-Test } & \multicolumn{2}{c}{ Pre-Test } & \multicolumn{2}{c}{ Post-Test } & \multicolumn{2}{c}{ Pre-Test } & Post-Test \\
\hline Measures & $M$ & $S D$ & $M$ & $S D$ & $M$ & $S D$ & $M$ & $S D$ & $M$ & $S D$ & $M$ & $S D$ \\
\hline MoCA & 21.38 & 5.55 & 24.13 & 2.17 & 20.80 & 2.94 & 22.00 & 3.09 & 16.78 & 5.02 & 19.56 & 4.88 \\
LM & 31.88 & 19.12 & 39.50 & 17.31 & 17.30 & 9.80 & 19.50 & 6.98 & 16.00 & 14.32 & 25.44 & 13.24 \\
FA & 33.50 & 12.73 & 39.13 & 14.32 & 30.20 & 7.66 & 29.70 & 8.43 & 25.00 & 5.92 & 25.56 & 9.29 \\
Lan & 152.00 & 7.21 & 153.50 & 5.29 & 152.90 & 12.41 & 158.00 & 4.37 & 138.33 & 9.94 & 146.44 & 7.28 \\
PS & 31.25 & 15.85 & 28.63 & 10.31 & 23.30 & 7.76 & 23.00 & 10.20 & 21.56 & 10.76 & 18.67 & 5.48 \\
EF & 43.50 & 8.09 & 49.88 & 7.22 & 44.00 & 2.75 & 46.20 & 7.98 & 39.44 & 6.27 & 43.33 & 8.69 \\
HADS Depression & 5.13 & 2.95 & 2.25 & 1.75 & 9.50 & 3.47 & 7.20 & 3.46 & 7.67 & 4.77 & 5.89 & 5.13 \\
HADS Anxiety & 4.63 & 2.00 & 4.50 & 2.78 & 8.20 & 4.26 & 6.90 & 5.09 & 7.78 & 3.23 & 5.44 & 2.88 \\
QOLIBRI & 62.38 & 11.81 & 66.25 & 11.65 & 47.40 & 12.63 & 51.50 & 18.44 & 46.89 & 19.53 & 58.11 & 21.06 \\
\hline
\end{tabular}

Note. EG = Experimental Group; CGI = Control Group I; CGII = Control Group II; MoCA = Montreal Cognitive Assessment; LM = Learning and Memory; FA = Focused Attention; Lan $=$ Language; $\mathrm{PS}=$ Processing Speed; $\mathrm{EF}=$ Executive Function; HADS = Hospital Anxiety and Depression Scale; QOLIBRI = Quality of Life after Brain Injury.

\section{Hypothesis Tests}

The following are the results of the mixed repeated-measures ANOVA performed to test this study's hypotheses.

Hypothesis 1. Participants in the VR-based NRP show marked improvement in cognitive, affective, and psychosocial functioning compared to people with ABI who do not participate in any intervention.

Cognitive domains. As for the MoCA total score, a marginal main effect was found for Group, $F=4.99, p=.076 ; \eta_{\mathrm{p}}^{2}=.625$, and a significant effect for Moment, $F=9.11, p=$ $.014 ; \eta_{\mathrm{p}}^{2}=.378$, but not for the Group * Moment interaction $(F<1)$.

Post-hoc intragroup analyses revealed a nearly significant effect between pre and post-test for EG, $t=2.06, p=.086$, as well as that for CGII, $t=2.21, p=.086$, revealing improved scores in both groups. Intergroup analyses revealed no significant differences in the pre-test and post-test assessments (both $p$ $>$.091).

As for learning and memory, whose raw results were calculated using Total Recall, Learning on the third trial, Delayed Recall, and by the Semantic Categories (IRD) of the HVLT instrument, analysis of variance revealed a nearly significant effect of Group, $F=4.02, p=.076$; $\eta_{\mathrm{p}}^{2}=.753$, and significant of Moment, $F=$ $14.90, p=.012 ; \eta_{\mathrm{p}}^{2}=.498$, with no Group ${ }^{*}$ Moment interaction effect found $(F<1)$.

Post-hoc intragroup analyses revealed a nearly significant difference between pre and post-test for EG, $t=2.37, p=.064$, and significant for CGII, $t=3.11, p=.021$, indicating improvement for both groups. Intergroup analyses revealed no significant differences in the pre-test assessment, nor the post-test assessment (both $p>.091$ ).

With regard to focused attention, whose raw results were extracted from the TMT (Forms A and B) and the WMS-III (SL and LNS), a nearly significant effect of Group, $F=4.77, p=.076$, $\eta_{\mathrm{p}}^{2}=.781$, and of Moment, $F=4.18, p=.071$; $\eta_{\mathrm{p}}^{2}=.218$, was found, with no effect of the Group * Moment interaction, $F=2.81, p=.342$.

Post-hoc intragroup analyses revealed a near 
significant difference between pre and post-test for the EG, $t=2.56, p=.064$, but not for CGII $(p=.792)$, resulting in an improvement only for the EG. Intergroup analyses showed no significant differences in either the pre-test or post-test assessment (both $p>$.091).

The raw results for the language domain, which were extracted from the Token Test, evidenced significant effects of the Group, $F=$ 9.42, $p=.048 ; \eta_{\mathrm{p}}^{2}=.736$, and of Moment, $F=$ 9.02, $p=.014 ; \eta_{\mathrm{p}}^{2}=.375$, but an effect of the Group * Moment interaction $(F=4.27, p=.342)$ was not found.

Post-hoc intragroup analyses revealed a significant difference between pre and post-test for CGII, $t=3.69, p=.012$, but not for EG ( $p$ $=.529$ ), indicating an improvement only in the former group. Intergroup analyses also showed significant differences in the pre-test assessment, $t=3.66, p=.006$, but not significant in the post-test $(p=.091)$.

As for processing speed in relation to the Word Reading and Color Naming scores of the Stroop Test, a nearly significant main effect of Group was found, $F=4.11, p=.076 ; \eta_{\mathrm{p}}{ }^{2}=.545$, with no effects found for Moment $(F=1.42, p=$ .253) nor for the Group ${ }^{*}$ Moment interaction $(F$ $<1)$.

Post-hoc analyses revealed no significant differences in either group (both $p>.454$ ) between the pre and post-test or between groups at any of the assessment times (both $p$ $>$.091).

Finally, regarding the executive functioning scores obtained from the Stroop Test (Reading Word-Color and the interference index) and the WCST (total number of errors; number of perseverative responses; number of perseverative errors; number of non-perseverative errors; number of complete categories and failures to maintain attitude) a significant effect was found for the variable Moment, $F=10.28, p=$ $.014 ; \eta_{\mathrm{p}}^{2}=.407$, and no main effect was found for Group $(F=2.52, p=.133)$, nor for Group * Moment interaction $(F<1)$.
Intragroup post-hoc analyses evidenced a near significant difference between pre and post-test for the EG, $t=2.74, p=.064$, but not for CGII $(p=.146)$, indicating improvement for the EG. Intergroup analyses showed no significant differences in either the pre or post-test assessment (both $p>.091$ ).

Affective Dimension. Repeated-measures ANOVA allowed us to see that there is no main effect of Group on the depression index, $F=3.09, p=.099$, but rather of Moment, $F=$ $8.26, p=.024 ; \eta_{\mathrm{p}}^{2}=.355$, and no effect of the Group * Moment interaction was found $(F<1)$. Post-hoc intragroup analyses showed a nearly significant difference between pre and post-test for the EG, $t=2.44, p=.056$, but not for CGII $(p=.130)$, indicating improvement for the EG. Intergroup analyses revealed no significant differences in the pre-test or post-test assessments (both $p>.148$ ).

As for anxiety, no significant effects were found for Group, $F=3.13, p=.099$, Moment, $F=3.13, p=.097$, nor for the Group*Moment interaction $(F=2.52, p=.508)$.

As for intragroup post-hoc analyses, results showed a near significant difference between pre and post-test for CGII, $t=2.45, p=.054$, but not for EG $(p=.903)$, indicating improvement for CGII. Intergroup analyses revealed nearly significant differences in the pre-test assessment, $t=2.34, p=.056$, in contrast to the post-test assessment $(p=.491)$.

Psychosocial dimension. No main effects of Group ( $F=2.47, p=.137$ ) or Group*Moment interaction $(F=1.28, p=.276)$ were found on quality of life, but a main effect of Moment was found, $F=5.39, p=.035 ; \eta_{\mathrm{p}}^{2}=.264$.

Post-hoc intragroup analyses showed a significant difference between pre and post-test for CGII, $t=2.51, p=.024$, but not for EG $(p$ $=.426$ ), indicating improved quality of life for CGII. Intergroup analyses revealed nearly significant differences at the pre-test assessment, $t$ $=1.89 p=.073$, but not at the post-test assessment $(p=.332)$. 
Hypothesis 2. The VR-based NRP produces results equivalent to those of the conventional program (face-to-face) in the various cognitive domains and psychosocial functioning.

Cognitive domains. As for general cognitive functioning, as measured by the raw MoCA scores, no main effect of Group was found, $(F<$ $1)$, nor of Group*Moment interaction $(F=1.32$, $p=.386$ ), but a main effect of Moment was found, $F=8.59, p=.030 ; \eta_{\mathrm{p}}^{2}=.349$.

Post-hoc intragroup analyses showed a significant difference between pre and post-test for the EG, $t=2.74, p=.045$, but not for the CGI $(p=.522)$, suggesting an improvement for the EG. At the intergroup level, no differences were found on either the pre-test or post-test (both $p>$.297).

Regarding the learning and memory scores extracted from the HVLT (Total Recall, Learning on the third trial, Delayed Recall, and Semantic Categories [IRD]), the analysis of variance revealed a nearly significant effect of Group, $F=7.64, p=$ .084 , and significant of Moment, $F=8.70, p=$ $.030, \eta_{\mathrm{p}}{ }^{2}=.352$, with no Group ${ }^{*}$ Moment interaction effect found $(F=2.65, p=.386)$.

Intragroup post-hoc analyses showed a significant difference between pre and post-test for the EG, $t=3.07, p=.042$, but not for the CGI $(p=.522)$, indicating improvement for the EG. Intergroup analyses showed no significant differences in the pre-test assessment ( $p=$ .222), but showed significant differences in the post-test assessment, $t=3.09, p=.036$.

In the focused attention scores (raw scores extracted from the TMT, Forms A and B, and the WMS-III, SL and LNS), the analysis of variance revealed no main effects of Group ( $F$ $=1.83, p=.390)$, nor Moment $(F=1.58, p=$ .272), nor of Group*Moment interaction ( $F=$ $2.52, p=.386)$. Post-hoc intragroup and intergroup analyses naturally revealed no significant effect (all $p>.125$ ).

Also, in the language results, obtained using the Token Test, the analysis of variance revealed no significant effect of Group $(F<1)$, of Moment
$(F=3.52, p=.119)$, nor of Group*Moment interaction $(F=1.05, p=.386)$. All post-hoc analyses were non-significant (all $p>.270$ ).

Regarding the processing speed results (raw results of the Word Reading and Color Naming of the Stroop Test), the analysis of variance revealed no significant effect of Group ( $F=$ $2.35, p=.390)$, nor of Moment or Group*Moment interaction (both $F<1$ ). The results of all post-hoc comparisons were, as expected, non-significant (all $p>$.297).

Finally, regarding the executive functioning results (raw results of the Stroop Test, Reading Word-Color and the interference index; and the WCST, total number of errors; number of perseverative responses; number of perseverative errors; number of non-perseverative errors; number of complete categories and failures to maintain attitude), a significant main effect of Moment was found, $F=6.30, p=.046$; $\eta_{\mathrm{p}}^{2}=.283$, but not of Group $(F<1)$, nor of Group*Moment interaction $(F=1.49, p=.386)$. Post-hoc intragroup analyses showed a significant difference between pre and post-test for the EG, $t=2.50, p=.046$, but not for the CGI $(p=.522)$. Intergroup analyses revealed no significant differences in either the pre-test or post-test assessment (both $p>$.297).

Psychosocial dimension. As for life satisfaction measures and emotional and physical factors extracted from the QOLIBRI, we found a main effect of Group, $F=6.30, p=.023 ; \eta_{\mathrm{p}}{ }^{2}=.578$, but not of Moment $(F=1.58, p=.228)$, nor of Group*Moment interaction $(F<1)$.

As for the intragroup post-hoc analyses, the results showed no significant differences between the pre and post-test for either group (both $p>$.348), but the intergroup analyses, we found significant differences in the pre-test assessment, $t=2.23, p=.035$, and in the post-test assessment, $t=2.20, p=.038$.

Hypothesis 3. The conventional program produces better results than the VR-based NRP in the affective domain.

For depression, repeated-measures ANOVA 
allowed us to find that there are significant effects of Group, $F=14.25, p=.004 ; \eta_{\mathrm{p}}{ }^{2}=$ .703 , and Moment, $F=11.69, p=.008 ; \eta_{\mathrm{p}}^{2}=$ .422 , and no effects of the Group*Moment interaction were found $(F<1)$. Post-hoc intragroup analyses showed a significant difference between pre and post-test for the EG, $t=2.55$, $p=.042$, and nearly significant for the CGI, $t=2.28, p=.074$. Intergroup analyses also revealed significant differences in the pre-test assessment, $t=3.02, p=.012$, and in the post-test assessment, $t=3.42, p=.004$.

As for anxiety, a nearly significant effect was found for Group, $F=3.28, p=.089$, and no effects were found for Moment, nor Group*Moment interaction (both $\mathrm{F}<1$ ). Post-hoc analyses only revealed a nearly significant difference between groups on the pre-test, $t=$ $1.95, p=.063$.

\section{DISCUSSION}

This study aimed to assess a VR-based holistic NRP in the rehabilitation of people with post-acute ABI, specifically at the cognitive, affective, and psychosocial levels. Three hypotheses were established and tested.

The hypothesis that participants in the VR-based NRP show improvement in cognitive, affective, and psychosocial functioning measures compared to people with $\mathrm{ABI}$ who do not participate in any intervention was partially confirmed by the results of this study. Significant cognitive-level improvements were observed in focused attention and executive functioning between the pre-test and post-test in the group that underwent the VR support rehabilitation program. The post-test results of the EG in these domains were better than those of the CGII, which did not benefit from any program. Also, regarding affective functioning, namely depression, the results indicate an improvement in the EG participants (which was not accompanied by an improvement in the group without intervention), demonstrating the benefits of our rehabilitation program.
The results for anxiety are exactly the opposite, and, incidentally, the same is true for psychosocial functioning. The fact that the groups were not initially paired on these variables offers a plausible explanation for these findings.

Improvements in general cognitive functioning, learning, and memory were also found in the EG. CGII also improved pre-test to post-test performance in the same cognitive domains, despite not having performed rehabilitation. Therefore, the improvement in these domains does not seem to be related to the rehabilitation program, indicating that these measures are sensitive to a learning effect or spontaneous recovery mechanisms that benefited both groups equally.

In the particular case of language, CGII even showed an improvement that was not matched in the EG, which may also be explained by the pairing between groups in this variable not having occurred at the beginning of the study.

As for the executive function, the marginal results of the intragroup analyses are explained by some authors who state that the contribution of neuropsychological tests to the constitution of outcome measures is sometimes limited, especially when it comes to mapping more complex deficits, as is the case of executive functioning, and it is difficult to translate test performance to the level of impairment or the rehabilitation goals (Chaytor et al., 2006). Also, Wilson (2009) agrees with the insufficiency of neuropsychological assessment instruments as the only measure of intervention outcome since most standardized tests have poor ecological validity. For these reasons, we conducted a multidomain study. Some authors (e.g., Chesnut et al., 1999; Wilson, 2009) draw attention to the fact that it is more pertinent to use standardized neuropsychological tests as intermediate measures in the rehabilitation process rather than as outcome measures.

As for the impacts of VR-supported NRP on cognitive and psychosocial dimensions compared to those of the conventional program 
(hypothesis 2), the former, unlike the latter, seems to have positive effects on general cognitive functioning, learning and memory, and executive functioning, and no significant differences were found in any of the other variables in the cognitive domain, nor the psychosocial domains.

As for the hypothesis that the conventional program produces better results than the VR-based NRP in the affective domain (H3), our program seems to have positive effects on depression, judging by the significant decrease in the values of the statistical test in both the EG and the CGI (face-to-face NRP). These results are surprising and, in fact, were not expected since the CGI benefited from individual and group psychotherapy sessions, which plausibly contributed to attenuate depressive symptoms, a component that was not present in the program offered to the EG participants. Additionally, anxiety levels did not change significantly in either group. However, it is possible to observe a slight improvement in the EG in clinical terms since the mean value in the pre-test suggests mild anxious symptomatology, reducing in the post-test to asymptomatic values. Therefore, contrary to expectations, these results cannot be placed in the service of confirming the benefits of individual and group psychological monitoring in holistic NR (Svendsen \& Teasdale, 2006; Svendsen et al., 2004).

Therefore, the results suggest that the holistic NRP supported in VICERAVI is at least equally effective to the counterpart, face-to-face administered program, with the results even suggesting superior effectiveness regarding training cognitive functions such as executive functioning or learning and memory.

To minimize the methodological problems frequently indicated in the literature, we tried to use adequate outcome measures and apply a clinical trial-type experimental design with control groups (active and passive), randomized whenever possible. Nevertheless, the study has some methodological limitations.
Given the nature of the intervention programs themselves, which involve groups with a maximum of 8-10 elements, we could not constitute larger samples. Instead, we followed the method proposed by Jacobson and Truax (1991), involving pre and post-intervention evaluation of the group that did our program, comparing it not only with a control group (CGII) with similar characteristics in terms of age, severity, and time after the injury that was not subjected to neuropsychological intervention (Grealy et al., 1999) but also with another control group (CGI) with similar characteristics that underwent a conventional intervention.

Although randomized groups give greater credibility to the results of studies on the effectiveness of clinical interventions, it should be noted that individual variables must be considered when defining the therapeutic plan. In this study, the individual characteristics of the participants were considered to adapt the whole cognitive and psychosocial rehabilitation plan, so the greater or lesser effectiveness of the intervention cannot but depend, to a certain extent, on the more or less adequate way in which such plans were carried out. Therefore, we acknowledge the importance of complementing the methodology understudy with the inclusion of measures of how the programs themselves are implemented and the achievement of therapeutic goals (Malec, 2001), thus adding value to the study of the impact of NR on VR.

Another limitation to be mentioned is the impossibility of participants interacting personally in daily life situations, which would make some of the activities of the psychosocial rehabilitation sessions using VR, such as the "hot seat," in which participants are asked to describe characteristics of one of the group members, much easier if there were a previous face-to-face contact, as in conventional rehabilitation programs.

Even in the presence of some methodological limitations, VR seems to be applicable to 
the neuropsychological rehabilitation of people with ABI. The results suggest that even better cognitive outcomes are achieved on certain measures, such as general cognitive functioning, learning and memory, and executive functioning, than those of conventional NRP, and that both have a positive impact on reducing depression, contributing to emotional well-being.

Studies on VR use in the neuropsychological rehabilitation of people with $\mathrm{ABI}$ have shown promising results, but its potential benefits need to be further studied. Moreover, to our knowledge, this is the first study to assess the use of virtual environments in holistic neuropsychological rehabilitation specifically. Thus, further studies on this topic are required to confirm our findings.

\section{CONCLUSION}

Participants in the VR-based NRP showed marked improvements in cognitive, affective, and psychosocial functioning compared to participants who did not participate in any intervention. Also, the VR-based NRP results were better than those of the conventional program regarding general cognitive functioning, learning and memory, and executive functioning. Finally, regarding the affective domain, the VR-based NRP produced results like the conventional program in reducing depression.

The VR may be a support to the NRP sessions of people with $\mathrm{ABI}$, contributing to reduce the discomfort, time, and cost of travel, as well as the expenses of face-to-face programs, and allowing people with ABI unable to travel to increase their interpersonal relationships. The results of this study illustrated the usefulness of VR in neuropsychological rehabilitation of ABI and the possibility of using this type of technology to provide rehabilitation programs, including those inspired by current holistic models, at the service of the people who need them.
Agradecimentos:

Nada declarado.

Conflito de Interesses:

Nada declarado.

Financiamento:

Nada declarado.

\section{REFERÊNCIAS}

Adams, R., Finn, P., Moes, E., Flannery, K., \& Rizzo, A. (2009). Distractibility in attention/deficit/hyperactivity disorder (ADHD): The virtual reality classroom. Child Neuropsychology, 15, 120-135. https://doi. org/10.1080/09297040802169077

Albani, G., Pignatti, R., Bertella, L., Priano, L., Semenza, C., Molinari, E., Riva, G., \& Mauro, A. (2002). Common daily activities in the virtual environment: a preliminary study in parkinsonian patients. Neurological Sciences, 23, 49-50. https://doi.org/10.1007/ s100720200064

Benjamini, Y., \& Hochberg, Y. (1995). Controlling the false discovery rate: a practical and powerful approach to multiple testing. Journal of the Royal Statistical Society. Series B (Methodological), 57(1), 289-300. https:// doi.org/10.2307/2346101

Ben-Yishay, Y. (2000). Post acute neuropsychological rehabilitation: A holistic perspective. In A.L., Christensen \& B., Uzzell (Eds.), International Handbook of Neuropsychological Rehabilitation. New York: Kluwer Academic/Plenum Publishers.

Ben-Yishay, Y., \& Diller, L. (2011). Handbook of Holistic Neuropsychological Rehabilitation: Outpatient Rehabilitation of Traumatic Brain Injury. New York: Oxford University Press.

Berg, E. A. (1948). A simple objective treatment for measuring flexibility in thinking. Journal of General Psychology, 39, 15-22. https://doi. org/10.1080/00221309.1948.9918159

Botella, C., Quero, S., Baños, R., Perpiña, C., Palacios, A., \& Riva, R. (2004). Virtual 
reality and psychotherapy. Studies in Health Technology and Informatics, 99, 37-54. https:// doi.org/10.3233/978-1-60750-943-1-37

Brandt, J., \& Benedict, R. H. B. (2001). Hopkins Verbal Learning Test-Revised. Professional manual. Lutz, FL: Psychological Assessment Resources, Inc.

Brickenkamp, R. (2002). Teste de atenção: Manual d2. Lisboa: Cegoc.

Chaytor, N., Schmitter-Edgecombe, M., \& Burr, R. (2006). Improving the ecological validity of executive functioning assessment. Archives of Clinical Neuropsychology, 21, 217-227. https://doi.org/10.1016/j.acn.2005.12.002

Chesnut, R.M., Carney, N., Maynard, H., Mann, N.C., Patterson, P., \& Helfand, M. (1999). Summary report: Evidence for the effectiveness of rehabilitation for persons with traumatic brain injury. Journal of Head Trauma Rehabilitation, 14(2), 176-88. https:// doi.org/10.1097/00001199-19990400000007

Cicerone, K.D., Langenbahn, D.M., Braden, C., Malec, J.F., Kalmar, K., Fraas, M., Felicetti, T., Laatsch, L., Harley, J.P., Bergquist, T., Azulay, J., Cantor, J., \& Ashman, T. (2011). Evidence-based cognitive rehabilitation: Updated review of the literature from 2003 through 2008. Archives of Physical Medicine and Rehabilitation, 92, 519-530. https://doi. org/10.1016/j.apmr.2010.11.015

Cicerone, K.D., Mott, T., Azulay, J., SharlowGalella, M.A., Ellmo, W.J., Paradise, S., \& Friel, J.C. (2008). A randomized controlled trial of holistic neuropsychologic rehabilitation after traumatic brain injury. Archives of Physical Medicine and Rehabilitation, 89, 2239-2249. https://doi.org/10.1016/j. apmr.2008.06.017

Coetzer, R. (2008). Holistic neurorehabilitation in the community: Is identity a key issue? Neuropsychological Rehabilitation, 18(5/6), 766-783. https://doi. org/10.1080/09602010701860266

Côté, S., \& Bouchard, S. (2008). Virtual reality exposure for phobias: A critical review. Journal of CyberTherapy \& Rehabilitation, 1(1), 75-92. Recuperado em 23 de maio de 2021, de https://www.researchgate.net/profile/ Giuseppe-Riva-2/publication/282312678_ From_virtual_to_real_body_Virtual_ reality_as_embodied_technology/ links/5616e54d08ae90469c611e13/Fromvirtual-to-real-body-Virtual-reality-asembodied-technology.pdf\#page $=73$

De Renzi, E., \& Vignolo, L.A. (1962). The Token Test: a sensitive test to detect receptive disturbances in aphasics. Brain, 85, 665-78. https://doi.org/10.1093/brain/85.4.665

Egan, J., Worrall, L., \& Oxenham, D. (2005). An internet training intervention for people with traumatic brain injury: Barriers and outcomes. Brain Injury, 19(8), 555-568. https://doi. org/10.1080/02699050400013659

Fernandes, S. (2013). Stroop: teste de cores $e$ palavras. Lisboa: CEGOC-TEA.

Freitas, S., Simões, M.R., Martins, C., Vilar, M., \& Santana, I. (2010). Estudos de adaptação do Montreal Cognitive Assessment (MoCA) para a população portuguesa. Avaliação Psicológica, 9(3), 345-357. Recuperado em 23 de maio de 2021, de http://pepsic.bvsalud.org/scielo. php? script $=$ sci_arttext $\&$ pid $=$ S 1677 04712010000300002\&lng $=$ pt\&tlng $=$ pt.

Gamito, P., Oliveira, J., Morais, D., Rosa, P., \& Saraiva, T. (2010). Serious games for serious problems: from ludicus to therapeuticus. In J.J., Kim (2011), Virtual Reality (Ed.), https://doi.org/10.5772/12870. Available from: http://www.intechopen.com/books/virtualreality/serious-games-for-serious-problems-fromludicus-to-therapeuticus.

Gaudino E. A., Geisler M. W., \& Squires N. K. (1995). Construct validity in the Trail Making Test: what makes Part B harder? Journal of Clinical and Experimental Neuropsycholgy, 17(4), 529-535. https://doi. org/10.1080/01688639508405143

Glantz, K., Rizzo, A., \& Graap, K. (2003). 
Virtual reality for psychotherapy: Current reality and future possibilities. Psychotherapy: Theory, Research, Practice, Training, 40(1/2), 55-67. https://doi.org/10.1037/00333204.40.1/2.55

Golden, C. (1978). Stroop colour and word test. Illinois: Stoelting Company.

Golden, C., \& Freshwater, S. (2002). Stroop Colour and Word Test Adult Version. A manual for clinical and experimental uses. (2a Ed.). Wood Dale, Illinois: Stoelting.

Grealy, M.A., Johnson, D.A., \& Rushton, S.K. (1999). Improving cognitive function after brain injury: the use of exercise and virtual reality. Archives of Psysical and Medical Rehabilitation, 80, 661-667. https://doi. org/10.1016/s0003-9993(99)90169-7

Guerreiro, S., Almeida, I., Fabela, S., Dores, A.R., \& Castro-Caldas, A. (2009). Avaliação de 5 anos de reabilitação neuropsicológica no Centro de Reabilitação Profissional de Gaia (CRPG). Re(habilitar) - Revista da ESSA, 8(9), 19-36.

Guerreiro, S., Almeida, I., Martins-Rocha, B., Dores, A.R., Vicente, S.G., Castro-Caldas, A., \& Barbosa, F. (2012). QOLIBRI - Uma medida específica de avaliação da qualidade de vida após lesão cerebral adquirida. In J. L. Pais Ribeiro, I. Leal, A. Pereira, A. Torres, I. Direito \& P. Vagos (Org.), Atas do $9^{\circ}$ Congresso Nacional de Psicologia da Saúde (pp. 571-578). Lisboa: Placebo, Editora LDA.

Heaton, R. K., Chelune, G. J., Talley, J. L., Kay, G. G. \& Curtiss, G. (2001). WCST - Test de Clasificación de Tarjetas de Wisconsin. $2^{\mathrm{a}}$ Edición. TEA Ediciones. Madrid.

Jacobson, N. S., \& Truax, P. (1991). Clinical significance: a statistical approach to defining meaningful change in psychotherapy research. Journal of consulting and clinical psychology, 59(1), 12-19. https://doi. org/10.1037//0022-006x.59.1.12

Jarmon, L., Traphagan, T., \& Mayrath, M. (2008). Understanding project-based learning in Second Life with pedagogy, training, and assessment trio. Educational Media International, 45(3), 157-176. https://doi. org/10.1080/09523980802283889

Jesus, L., \& Aguiar, V. (2014). Token Test (Renzi \& Faglioni 1978) - Versão Portuguesa. Available from Advanced Communication and Swallowing Assessment (ACSA) http:// acsa.web.ua.pt

Kenny, P., Parsons, T.D., Pataki, C., Pato, M., St-George, C., Sugar, J., \& Rizzo, A.A. (2008). Virtual Justina: A PTSD virtual patient for clinical classroom training. Annual Review of Cybertherapy and Telemedicine, 6(1), 113-118. Recuperado em 23 de maio de 2021, de https://ict.usc.edu/pubs/ Virtual\%20Justina-\%20A\%20PTSD\%20 Virtual\%20Patient\%20for\%20Clinical\%20 Classroom\%20Training.pdf.

Kenny, P., Parsons, T.D., Rothbaum, B., Difede, J., Reger, G., \& Rizzo, A.A. (2009). Optimizing clinical training for the treatment of PTSD using virtual patients. Annual Review of Cybertherapy and Telemedicine, 264-268. https://doi.org/10.3233/978-1-60750-0179-264

Lengenfelder, J., Schultheis, M. T., Al-Shihabi, T., Mourant, R., \& DeLuca, J. (2002). Divided attention and driving: a pilot study using virtual reality technology. The Journal of head trauma rehabilitation, 17(1), 26-37. https:// doi.org/10.1097/00001199-20020200000005

Leon-Carrion, J., Dominguez-Morales, M.R., \& Martin, J.M.B. (2005). Driving with cognitive deficits: neurorehabilitation and legal measures are needed for driving again after severe traumatic brain injury. Brain Injury, 19(3), 213-219. https://doi. org/10.1080/02699050400017205

Malec J. F. (2001). Impact of comprehensive day treatment on societal participation for persons with acquired brain injury. Archives of physical medicine and rehabilitation, 82(7), 885-895. https://doi.org/10.1053/ apmr.2001.23895 
Nasreddine, Z. S., Phillips, N. A., Bédirian, V., Charbonneau, S., Whitehead, V., Collin, I., Cummings, J. L., \& Chertkow, H. (2005). The Montreal Cognitive Assessment, MoCA: a brief screening tool for mild cognitive impairment. Journal of the American Geriatrics Society, 53(4), 695-699. https:// doi.org/10.1111/j.1532-5415.2005.53221.x

Pais-Ribeiro, J., Silva, I., Ferreira, T., Martins, A., Meneses, R., \& Baltar, M. (2007). Validation study of a portuguese version of the Hospital Anxiety and Depression Scale. Psychology, health \& medicine, 12(2), 225-237. https:// doi.org/10.1080/13548500500524088

Pioggia, G., Igliozzi, R., Sica, M.L., Ferro, M., Muratori, F., Ahluwalia, A., \& Rossi, D. (2008). Exploring emotional and imitational android-based interactions in autistica spectrum disorders. Journal of Cybertherapy $\mathcal{E}$ Rehabilitation, 1(1), 49-61. Recuperado em 23 de maio de 2021, de http://www. ilc.cnr.it/ ferro/publications/Exploring Emotional_and_Imitational_Android_ based_Interactions_in_Autistic_Spectrum _ Disorders.pdf.

Pietrapiana, P., Tamietto, M., Torrini, G., Mezzanato, T., Rago, R., \& Perino, C. (2005). Role of premorbid factors in predicting safe return to driving after severe TBI. Brain injury, 19(3), 197-211. https://doi. org/10.1080/02699050400017197

Riva, G. (2009). Virtual reality: an experiential tool for clinical psychology. British Journal of Guidance \& Counselling, 37(3), 337-345. $\quad$ https://doi. org/10.1080/03069880902957056

Riva, G., Bacchetta, M., Baruffi, M., \& Molinari, E. (2002). Virtual-reality-based multidimensional therapy for the treatment of body image disturbances in binge eating disorders: a preliminary controlled study. IEEE transactions on information technology in biomedicine: a publication of the IEEE Engineering in Medicine and Biology Society, 6(3), 224-234. https://doi.org/10.1109/titb.2002.802372
Riva, G., Bacchetta, M., Cesa, G., Conti, S., \& Molinari, E. (2004). The use of VR in the treatment of eating disorders. Studies in Health Technology and Informatics, 99, 121-163. https://doi.org/10.3233/978-1-60750-9431-121

Rizzo, A. A., Buckwalter, J. G., Bowerly, T., van der Zaag, C., Humphrey, L., Neumann, U., Chua, C., Kyriakakis, C., van Rooyen, A., \& Sisemore, D. (2000). The virtual classroom: A virtual reality environment for the assessment and rehabilitation of attention deficits. CyberPsychology $\mathcal{E}$ Behavior, 3(3), 483-499. https://doi. org/10.1089/10949310050078940

Rizzo, A., Graap, K., Pair, J., Reger, G., Treskunov, A. \& Parsons, T. (2006). User-centered design driven development of a virtual reality therapy application for Iraq war combatrelated post traumatic stress disorder. In: Proceedings of the 6th International Conference on Disability, Virtual Reality and Associated Technology (ICDVRAT2006), Denmark, UK.

Rizzo, A.A., Schultheis, M., Kerns, K.A., \& Mateer, C. (2004). Analysis of assets for virtual reality applications in neuropsychology. Neuropsychological Rehabilitation, 14(1/2), 207-239. https://doi. org/10.1080/09602010343000183

Rose, F. D., Brooks, B. M., Attree, E. A., Parslow, D. M., Leadbetter, A. G., McNeil, J. E., Jayawardena, S., Greenwood, R., \& Potter, J. (1999). A preliminary investigation into the use of virtual environments in memory retraining after vascular brain injury: indications for future strategy?. Disability and rehabilitation, 21(12), 548-554. https://doi. org/10.1080/096382899297206

Schultheis, M.T., \& Rizzo, A.A. (2001). the application of virtual reality technology in rehabilitation. Rehabilitation Psychology, 46(3), 296-311. https://doi.org/10.1037//00905550.46.3.296

Schultheis, M.T., Himelstein, J., \& Rizzo, A.A. 
(2002). Virtual reality and neuropsychology: upgrading the current tools. Journal of Head Trauma Rehabilitation, 17(5), 378-394.

Svendsen, H.A., \& Teasdale, T.W. (2006). The influence of neuropsychological rehabilitation on symptomatology and quality of life following brain injury: A controlled long-term follow-up. Brain Injury, 20(12), 1295-1306. https://doi. org/10.1080/02699050601082123

Svendsen, H.A., Teasdale, T.W., \& Pinner, M. (2004). Subjective experience in patients with brain injury and their close relatives before and after a rehabilitation programme. Neuropsychological Rehabilitation, 14(5), 495-515. https://doi. org/10.1080/09602010343000318

Truelle, J. L., Koskinen, S., Hawthorne, G., Sarajuuri, J., Formisano, R., Von Wild, K., Neugebauer, E., Wilson, L., Gibbons, H., Powell, J., Bullinger, M., Höfer, S., Maas, A., Zitnay, G., Von Steinbuechel, N., \& Qolibri Task Force (2010). Quality of life after traumatic brain injury: the clinical use of the QOLIBRI, a novel disease-specific instrument. Brain injury, 24(11), 1272-1291. https://doi.org/10.3109/02699052.2010.50 6865

von Steinbüchel, N., Wilson, L., Gibbons, H., Hawthorne, G., Höfer, S., Schmidt, S., Bullinger, M., Maas, A., Neugebauer, E., Powell, J., von Wild, K., Zitnay, G., Bakx, W., Christensen, A. L., Koskinen, S., Formisano, R., Saarajuri, J., Sasse, N., Truelle, J. L., \& QOLIBRI Task Force (2010). Quality of life after brain injury (QOLIBRI): scale validity and correlates of quality of life. Journal of neurotrauma, 27(7), 1157-1165. https://doi. org/10.1089/neu.2009.1077
Wechsler, D. (1998). WMS - III Administration and scoring manual (3th Ed.). London: The Psychological Corporation.

Wiederhold, B.K., \& Wiederhold, M.D. (2008). Virtual Reality for posttraumatic stress disorder and stress inoculation training. Journal of CyberTherapy \& Rehabilitation, 1(1), 23-35.

Wilson B. A. (2000). Compensating for cognitive deficits following brain injury. Neuropsychology review, 10(4), 233-243. https://doi.org/10.1023/a:1026464827874

Wilson, B.A. (2002). Towards a comprehensive model of cognitive rehabilitation. Neuropsychological Rehabilitation, 12(2), 97-110. https://doi. org/10.1080/09602010244000020

Wilson, B.A. (2009). Evidence for the effectiveness of neuropsychological rehabilitation. In B. Wilson, F. Gracey, J. Evans, \& A. Bateman, (Eds.), Neuropsychological Rehabilitation: Theory, models, therapy and outcomes (pp. 22-36). Cambridge: Cambridge University Press.

Yellowlees, P.M., \& Cook, J.N. (2006). education about hallucinations using an internet virtual reality system: A qualitative survey. Academic Psychiatry, 30(6), 534-539. https:// doi.org/10.1176/appi.ap.30.6.534

Zigmond, A. S., \& Snaith, R. P. (1983). The hospital anxiety and depression scale. Acta psychiatrica Scandinavica, 67(6), 361-370. https://doi.org/10.1111/j.1600-0447.1983. tb09716.x 